\title{
End-of-life care in the Pediatric Intensive Care Units: Challenges and ethical principles
}

\section{Brenda M. Morrow}

In this issue, Siddiqui, et al. present a report on the mortality patterns in Pediatric Intensive Care Units (PICU) in Pakistan, a developing country. ${ }^{[1]}$ It is difficult to interpret the apparently high mortality rate of almost $13 \%$ without the context of average predicted mortality on admission (i.e. standardized mortality rates [SMR]). Future studies would benefit from the use of SMR, to track performance of the PICU over time and to compare outcomes with other units nationally and internationally. ${ }^{[2]}$

Similar to previous reports, the majority of deaths in the accompanying study ${ }^{[1]}$ occurred following limitation of life-sustaining treatments (including "do not resuscitate" orders and "withdrawal of life-support treatment"). ${ }^{[3]}$ The reader is left to interpret the meaning of "life-support treatment." This could include any or all of nutritional support, antibiotic treatment, mechanical ventilation, inotropes, fluid therapy, etc.

Faced with the difficult decision on whether, when and how to transition from life-sustaining treatment to end-of-life care, advice should ideally be sought from experienced clinical ethics committees. Decisions and processes should be guided by the following fundamental ethical principles: ${ }^{[4]}$

1. Respect for persons, autonomy and the right to self-determination: This includes respect of religious and cultural beliefs and practices and the provision of appropriate psychosocial support.

- The issue of obtaining informed consent from parents for withdrawal of life-sustaining therapy for their child is an important component of this ethical principle. It is unclear from the

From:

Department of Paediatrics and Child Health, University of Cape Town,

Cape Town, South Africa

\section{Correspondence:}

Dr. Brenda M. Morrow, Department of Paediatrics and Child Health, University of Cape Town, Cape Town, South Africa.

E-mail: Brenda.morrow@uct.ac.za

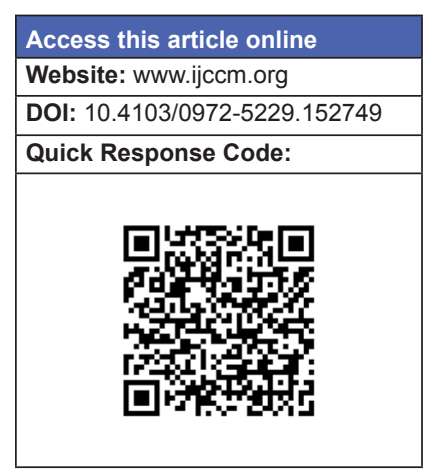

accompanying study how consent was obtained, and by whom. While the family should always be fully informed and understand the reasons for limiting or withdrawing active treatment, it may not always be appropriate to obtain formal parental consent. Where required by legislation, consent should be taken in a compassionate manner with ample time given to discussion, including the extended family and community where appropriate. ${ }^{[3]}$ The potential for explicit or implicit coercion in parental decision-making must be acknowledged, owing to the power imbalance between physician and parent. ${ }^{[5]}$

- There is the concern that parents are not always able to make fully informed or voluntary choices about their critically ill child's treatment. Parents who are already incapacitated by grief, despair and exhaustion, may experience an added burden of harm by being approached to sign a "do not resuscitate" order or to provide consent for the withdrawal of life-sustaining therapy for their child, especially when death is inevitable. ${ }^{[6]}$ In this case, asking for consent with a view to respecting parental autonomy may, unnecessarily, be seen as asking a parent to sign their child's death warrant. 
- Unilateral decision-making, either by the physician or parent/s is unlikely to be in the best interests of the child. ${ }^{[7]}$ Rather, the approach should be one of partnership and collaboration in the decision-making process. ${ }^{[8]}$ It makes sense for the attending physician to present his/her recommendations for management with clear reasons, rather than presenting the family with a list of therapeutic options to choose from. ${ }^{[9]}$ This may lessen the guilt and psychological after-effects often associated with end-of-life decision-making. ${ }^{[6,10]}$

- In the critical care context, most children are unable to contribute to the decision-making process. Where children are sufficiently cognitively aware and developmentally able to assimilate information relating to treatment options, they should also be involved in the process in a developmentally appropriate way. ${ }^{[8]}$ They should be allowed to ask questions, to express fears or worries, and to express their opinions and preferences to the extent that they are able to do so.

2. Beneficence and its corollary, nonmaleficence: This principle requires that harm be avoided or minimized and potential benefits to the child and family be maximized. Although critical care potentially offers a number of life-sustaining interventions, there may come a point when implementing these interventions no longer serves the best interests of the child patient.

- There are five accepted circumstances under which withholding or withdrawing curative medical therapy may be considered: [11]

i. The child is brain dead (according to specific criteria)

ii. The child is in a permanent vegetative state

iii. "No chance" situation - where life-sustaining therapy only serves to delay death without relieving suffering

iv. "No purpose situation" - the child may survive with curative treatment but would be left with severe physical or mental impairment

v. "Unbearable situation" - where, in the face of progressive and irreversible illness, the burden (in terms of pain, disability, emotional suffering or other factors substantially impacting on quality of life) of further treatment is more than could be borne.

- It is unclear which categories were most prevalent in the study by Siddiqui, et al.$^{[1]}$ Importantly, the decision to withhold or withdraw life-sustaining treatment should never be seen as an end in itself. While the goals of care change; for example to ease suffering, reduce pain, and promote comfort; holistic, multidisciplinary care of the child and their family should never stop. ${ }^{[3]}$

3. Justice: One statement made in the accompanying paper is deeply concerning; that in Pakistan, and likely in many resource-constrained regions across the world, PICU care is only offered to those with sufficient financial resources (middle to high-income families).${ }^{[1]}$ In such cases, the decision to withdraw active therapy in PICU may be at least partly resource-driven, to avoid the excessive costs of prolonged PICU care. Is it appropriate to give these parents the mandate to withdraw active treatment; when the decision may be resource-based and not necessarily with the child's best interests paramount?

- Presumably, the children of less affluent parents are left to die outside of PICU; with the subsequent benefits as well as the ethical burdens of PICU care borne only by the rich. The fundamental global injustice of unequal access to PICU care urgently needs to be redressed.

In striving to save lives in the PICU, we should never forget the more important goals of management: to "cure sometimes, to relieve often, (and) to comfort always" (Hippocrates). When a child's death is inevitable, we owe it to that child and their family to ensure that the experience of death is as positive as possible, and to minimize any associated pain, discomfort, guilt and self-doubt.

In the words of Cicely Saunders, hospice founder, "How people die remains in the memories of those who live on."

\section{References}

1. Siddiqui, et al. Mortality patterns among critically ill children in a paediatric intensive care unit of a developing country. Indian J Crit Care Med 2015;19:147-50.

2. Duncan AW. The burden of paediatric intensive care: An Australian and New Zealand perspective. Paediatr Respir Rev 2005;6:166-73.

3. Polikoff LA, McCabe ME. End-of-life care in the pediatric ICU. Curr Opin Pediatr 2013;25:285-9.

4. The National Commission for the Protection of Human Subjects of Biomedical and Behavioural Research. The Belmont Report: Ethical 
Principles and Guidelines for the Protection of Human Subjects of Research. Washington, DC; 1979.

5. Kissoon N, d'Agincourt-Canning L. Death in the ICU: When comfort is therapeutic. Crit Care Med 2014;42:2147-8.

6. Mercurio MR, Murray PD, Gross I. Unilateral pediatric "do not attempt resuscitation" orders: The pros, the cons, and a proposed approach. Pediatrics 2014;133 Suppl 1:S37-43.

7. de Vos MA, Seeber AA, Gevers SK, Bos AP, Gevers F, Willems DL. Parents who wish no further treatment for their child. J Med Ethics 2015;41:195-200.

8. British Medical Association. Withholding and Withdrawing Life-Prolonging Medical Treatment. Guidance for Decision Making. $3^{\text {rd }}$ ed. United Kingdom: Blackwell Publishing; 2007.

9. American Academy of Pediatrics Committee on Bioethics:
Guidelines on foregoing life-sustaining medical treatment. Pediatrics 1994;93:532-6.

10. Truog RD. Is it always wrong to perform futile CPR? N Engl J Med 2010;362:477-9.

11. Nuffield Council on Bioethics. Critical Care Decisions in Fetal and Neonatal Medicine: Ethical Issues. Cardiff: Nuffield Council on Bioethics; 2006.

How to cite this article: Morrow BM. End-of-life care in the Pediatric Intensive Care Units: Challenges and ethical principles. Indian J Crit Care Med 2015;19:133-5.

Source of Support: Nil, Conflict of Interest: None declared.

\section{"Quick Response Code" link for full text articles}

The journal issue has a unique new feature for reaching to the journal's website without typing a single letter. Each article on its first page has a "Quick Response Code". Using any mobile or other hand-held device with camera and GPRS/other internet source, one can reach to the full text of that particular article on the journal's website. Start a QR-code reading software (see list of free applications from http://tinyurl.com/ yzlh2tc) and point the camera to the QR-code printed in the journal. It will automatically take you to the HTML full text of that article. One can also use a desktop or laptop with web camera for similar functionality. See http://tinyurl.com/2bw7fn3 or http://tinyurl.com/3ysr3me for the free applications. 